\title{
La investigación de la recepción televisiva en México
}

Elsa Patricia García Núñez de Cáceres Maestría en Comunicación del ITESM, Campus Monterrey

Los efectos de la internacionalización de las industrias culturales en las identidades culturales y la búsqueda de estrategias que contrarresten los efectos de la globalización, la homogeneización y la estereotipación resultantes de la transnacionalización de la comunicación, corresponden a dos de las once categorías temáticas que 84 especialistas del área de la comunicación internacional propusieron para una nueva agenda de investigación sobre comunicación intemacional (Rota y Rodríguez, 1995).

El fenómeno denominado globalización, la transnacionalización de los productos culturales, la transculturalización y sus implicaciones conforman algunas de la preocupaciones generalizadas de los académicos, situación que se ha acentuado gracias a la creación de bloques económicos alrededor del mundo.

El posible impacto generado por los flujos de mensajes transnacionales y sus repercusiones en la identidad cultural ha sido ampliamente estudiado desde la perspectiva del imperialismo cultural. Como señala Biltereyst (1995: 247) el argumento central en este sistema de ideas versa sobre la posibilidad de severos efectos negativos, como lo pueden ser: sincronización cultural, alienación, homogeneización y dominación. Los productos culturales transnacionalizados son vistos como altamente estandarizados y producidos bajo un contexto capitalista. Bajo este paradigma de dependencia las audiencias son conceptualizadas como pasivas y manipulables y los mensajes como hegemónicos.

La corriente definida como culturalista, desde su perspectiva, ha abordado de diferente manera el problema, enfocándose en la recepción de los mensajes transnacionales. A partir de este enfoque se asume que el receptor es activo (Orozco: 1994). La polisemia -entre otros factores- permite dicha 'actividad' ya que; "[...] posibilita a los miembros de la audiencia la producción de diferentes <videncias>". La conceptualiza- 
ción de las mediaciones "[...] como procesos de estructuración derivados de acciones concretas o intervenciones en el proceso de recepción [...]" (Orozco, 1994:73-74). Dichas mediaciones tienen como origen diversas fuentes. De entre las que plantea Orozco tenemos: la cultura, la política, la economía, el estrato social, el género, la edad, la etnicidad, los medios masivos de comunicación, las condiciones situacionales y contextuales, las instituciones y los movimientos sociales. Los mensajes desde este enfoque son concebidos como polisémicos, conteniendo dentro de un mismo texto mensajes hegemónicos y alternativos. Lozano (1996) atribuye esta naturaleza de los mensajes a que durante el proceso de producción muchos de los condicionantes -entre ellos individuales, externos, organizacionales- se contraponen entre sí. Otra explicación es aquella en la que resalta " [...] la necesidad de captar amplios y diversos grupos con distintos niveles culturales y visiones ideológicas" (Lozano, 1996: 171-172).

Aunque el enfoque culturalista suaviza las preocupaciones sobre la pasividad de las audiencias muchos académicos mexicanos. siguen dedicando sus esfuerzos a indagar sobre la posible influencia de la transculturalización en la identidad cultural mexicana, debido al gran desbalance en el intercambio de productos culturales entre los países desarrollados y los subdesarrollados.

El objeto de este trabajo es hacer una revisión de los principales estudios empíricos de recepción televisiva en México, ya que este medio transmite una alta cantidad de mensajes transnacionales. El propósito es brindar una visión integrada de los hallazgos que se tienen en este sentido, para determinar qué sabemos sobre dicho tema hasta el momento.

\section{Metodología}

Después de una revisión de la literatura se identificaron 19 investigaciones empíricas recientes que tenían una marcada acentuación en el acercamiento al receptor. ${ }^{1}$ Para brindar mayor claridad en la presentación de lo encontrado se clasificaron las investigaciones de acuerdo con el carácter de la técnica utilizada, esto es, cuantitativa o cualitativa. Los estudios cuantitativos que conformaron la base del presente análisis se presentan con

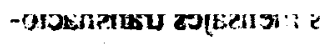

1 Debido a las dificultades en la circulación de libros y revistas académicas en el pais, esta lista puede contener omisiones importantes. Por lo tanto, no existe la pretensión de que sea exhaustiva ni de que incluya las más importantes. 
base en una categorización que se diseñó a partir del sistema en que se recibió la oferta televisiva (TV aérea, sistemas de cable y parabólica). Los estudios cualitativos se clasificaron en función de la fuente de mediación que se estudió como precondicionante en la recepción de los mensajes televisivos. A partir de esta clasificación de las investigaciones se analizaron los distintos hallazgos obtenidos para finalmente obtener una visión global que describa la recepción televisiva en México.

\section{¿A qué se exponen los televidentes?}

Las investigaciones sobre la recepción televisiva en México realizadas con técnicas cuantitativas se presentan a continuación. Estos estudios responden en forma general a la pregunta: "¿Qué tanto se exponen las audiencias mexicanas a los mensajes transnacionales?".

Esta primera parte incluye aquellas investigaciones que analizaron la oferta televisiva aérea.

González (1994) realizó un análisis en 1987 en Colima en el que se enfocó en la recepción de la telenovela (como género televisivo). El autor encontró que el canal preferido por los informantes fue el Canal 2 nacional "... el de las estrellas". En general, los encuestados preferían la programación nacional. En cuanto a la exposición a telenovelas, en todos los estratos declararon verlas, siendo el estrato bajo el que más se exponía a ellas y el estrato alto el que menos con un $63 \%$. Lo anterior indica que más de la mitad de la muestra se exponía a este género televisivo, que en esa ciudad eran sólo de producción nacional.

Por esas mismas fechas González (1993) realizó otro estudio en la misma línea, pero en esta ocasión incluyó las ciudades de México, Guadalajara, Puebla, León y Veracruz, teniendo como población seis ciudades (el análisis cualitativo de este proyecto se presentará en la siguiente sección). Los hallazgos que nos conciernen son los siguientes: al igual que en el caso exclusivo de Colima, más de la mitad de las personas de los tres estratos sociales declararon exponerse a las telenovelas. Según la información proporcionada por el investigador, éstas eran producidas nacionalmente, lo que nos indica que al menos la mitad de las muestras de estas ciudades se expusieron a productos culturales de corte nacional. De entre los géneros preferidos se encuentra la telenovela en primer lugar y en segundo acción y drama. Lo anterior es otro indicador de la preferencia de los productos culturales nacionales por encima de los extranjeros, ya que los géneros de acción y drama son producidos mayormente en los Estados Unidos. 
En Guadalajara, Aceves (1991) efectuó en 1989 un acercamiento a la relación oferta-consumo. Tomando en cuenta la oferta televisiva aérea, Aceves encontró que en esa ciudad el canal preferido era el Canal 2 nacional y que en general la gente prefería la oferta nacional.

Es importante hacer notar que en los estudios antes mencionados los rangos de edad de las poblaciones muestra es de 10 años en adelante.

Conocer patrones de consumo en la frontera norte y, específicamente, en Nuevo Laredo fue uno de los objetivos de Lozano (1994). La encuesta de este estudio fue aplicada en 1991. Como podemos observar en el Cuadro 1, los alumnos de secundaria tenían como canal preferido el canal 2 nacional, el estrato que más se expuso a la TV fue el alto, en general fue preferida la programación de procedencia nacional y sus géneros preferidos fueron la telenovela y los cómicos. Resultados contrarios a lo que pudiera esperarse si tomamos en cuenta que es una ciudad fronteriza del norte y pudiera pensarse que los jóvenes se exponen más a los mensajes extranjeros.

Los resultados de los siguientes trabajos que se muestran fueron realizados con la intención de conocer hábitos de consumo y preferencias televisivas en los jóvenes de Ciudad de México (Figueroa, 1996), Irapuato (Blanco, 1996), Monterrey (Díaz, 1995) y (de la Garza, 1996), y de Zacatecas (Olvera, 1995). Con miras a brindar una base para posteriores estudios que pueden determinar si los mensajes transnacionales que estas ciudades reciben influyen en la identidad cultural de sus jóvenes.

De lo que se destaca en los datos del Cuadro 1 , tenemos que de las cuatro ciudades sólo la Ciudad de México oferta más programación nacional con un $50.86 \%$. Y contrario a lo que pudiera concluirse -debido a que son quienes tienen más oferta nacional-, los jóvenes de esta ciudad prefieren la producción extranjera. Esto se ve reflejado en la preferencia de canal, pues en esta ciudad es el canal 5 XHGC el más visto por sobre el resto de los canales tno hay que perder de vista que este canal contiene dentro de su programación un $87.75 \%$ de programas extranjeros (Figueroa, 1996: 53). En Irapuato también prefieren la programación extranjera por sobre la nacional, lo cual se explica en cierta medida ya que los estratos que prefieren los programas de procedencia extranjera son dos; el medio y el alto, siendo así, el único caso en que más de un estrato prefiere lo no nacional.

La audiencia de Zacatecas muestra un comportamiento contrario del resto de las audiencias, ya que el estrato alto es el que más se expone a la TV -en Irapuato es el medio, en Monterrey (en las dos investigaciones) y en la Ciudad de México es el estrato bajo el que se expone más a la TV-, y el estrato bajo se expone mayormente a la programación 
ofertada por otros paises. Por lo que toca a los estudios de Ciudad de México y los dos de Monterrey es el estrato alto el que prefiere exponerse a la programación extranjera.

En estas cuatro ciudades los hombres prefieren los programas extranjeros y las mujeres los programas nacionales, a excepción del último estudio realizado en Monterrey (de la Garza, 1996) en donde independientemente del género, la audiencia prefiere la producción nacional tanto como la extranjera. La autora le atribuye esta situación al factor edad, ya que la muestra está basada en estudiantes de preparatoria, estableciendo que a mayor edad mayor preferencia por los programas extranjeros (de la Garza, 1996: 159).

A excepción de Irapuato y Ciudad de México, en las demás ciudades del país (Colima, Guadalajara, Nuevo Laredo, Monterrey y Zacatecas) los encuestados expresaron preferir la prgramación nacional. En cuanto al canal predilecto (al preguntar de manera general y sin tomar en cuenta el estrato social) se encontró una gran uniformidad en todas la ciudades -excepto en la de México-la preferencia por el canal 2 nacional "El canal de las estrellas" se hizo notar (Colima, Guadalajara, Irapuato, Nuevo Laredo, Monterrey y Zacatecas).

En su investigación sobre el consumo de las telenovelas, González (1993: 320) encontró que, " [....] al parecer, a medida que aumenta el tamaño de la ciudad disminuye el promedio de telenovelas diarias que se ven". Lo anterior se puede apoyar en tanto que en las ciudades de Irapuato y Nuevo Laredo que son proporcionalmente más chicas que Guadalajara, Monterrey y México tienen como género preferido la telenovela -entre las dos primeras menciones. Situación que no se pudo proyectar a Irapuato ya que esta población declaró su predileción por la programación extranjera y sus géneros preferidos fueron las películas y los programas cómicos. Lo anterior se afirma sin olvidar que la unidad de análisis de estos últimos estudios fueron jóvenes de entre 12 y 15 años, mientras en el estudio de González el rango de edad era de 10 en adelante. Conviene aclarar que por tanto a las variables de estrato social, edad y sexo hay que agregar el tipo y tamaño de la población.

De esta manera tenemos en los estudios cuantitativos analizados anteriormente que las personas encuestadas en los distintos puntos del país prefieren en su mayoría lo nacional por encima de lo extranjero. Aunque hay cierto consumo de lo extranjero, la mayor parte prefiere ver las producciones mexicanas. 


\section{Cuadro 1}

\section{Relación de las investigaciones similares que se han hecho en los noventa acerca de la recepción de la oferta televisiva}

\begin{tabular}{|c|c|c|c|c|c|c|}
\hline Ciudad & $\begin{array}{l}\text { Irapuato } \\
\text { Secundaria }\end{array}$ & $\begin{array}{l}\text { México } \\
\text { Secundaria }\end{array}$ & $\begin{array}{l}\text { Monterrey } \\
\text { Secundaria }\end{array}$ & $\begin{array}{l}\text { Zacatecas } \\
\text { Secundaria } \\
\end{array}$ & $\begin{array}{l}\text { Laredo } \\
\text { Secundaria } \\
\end{array}$ & $\begin{array}{l}\text { Monterrey } \\
\text { Preparatoria }\end{array}$ \\
\hline $\begin{array}{l}\text { Oferta: } \\
\text { Extranjera } \\
\text { Nacional } \\
\end{array}$ & $\begin{array}{l}73.88 \% \\
26.11 \% \\
\end{array}$ & $\begin{array}{l}49.14 \% \\
50.86 \% \\
\end{array}$ & $\begin{array}{l}75 \% \\
25 \% \\
\end{array}$ & $\begin{array}{l}55 \% \\
45 \% \\
\end{array}$ & : & $\begin{array}{l}\text { mayor } \\
\text { menor }\end{array}$ \\
\hline $\begin{array}{l}\text { Canal } \\
\text { preferido }\end{array}$ & $\begin{array}{c}2 \\
\text { nacional } \\
\end{array}$ & $\begin{array}{c}5 \\
\text { nacional } \\
\end{array}$ & $\begin{array}{c}2 \\
\text { nacional }\end{array}$ & $\begin{array}{c}2 \\
\text { nacional }\end{array}$ & $\therefore \begin{array}{c}2 \\
\text { nacional }\end{array}$ & $\begin{array}{c}2 \\
\text { nacional }\end{array}$ \\
\hline$>$ exp.tv $*$ & medio & bajo & bajo & alto & alto & bajo \\
\hline $\begin{array}{l}\text { >exp.tv* } \\
\text { extranjera }\end{array}$ & $\begin{array}{c}\text { medio } \\
\text { alto }\end{array}$ & alto & alto & bajo & $\therefore$ alto & alto \\
\hline $\begin{array}{l}\text { Preferencia } \\
\mathrm{H} \\
\mathrm{M}\end{array}$ & $\begin{array}{c}\text { extranjera } \\
\text { nacional }\end{array}$ & $\begin{array}{c}\text { extranjera } \\
\text { nacional }\end{array}$ & $\begin{array}{c}\text { extranjera } \\
\text { nacional }\end{array}$ & $\begin{array}{c}\text { extranjera } \\
\text { nacional }\end{array}$ & ard 2? & $\begin{array}{l}\text { ambas } \\
\text { ambas }\end{array}$ \\
\hline $\begin{array}{l}\text { Preferencia } \\
\text { de oferta en } \\
\text { general }\end{array}$ & extranjera & extranjera & nacional & nacional & nacional & nacional \\
\hline $\begin{array}{l}\text { Géneros } \\
\text { preferidos }\end{array}$ & $\begin{array}{l}\text { películas } \\
\text { cómicos }\end{array}$ & $\begin{array}{l}\text { aventuras } \\
\text { infantiles }\end{array}$ & $\begin{array}{c}\text { aventuras } \\
\text { caricaturas }\end{array}$ & $\begin{array}{c}\text { película } \\
\text { tv-novela }\end{array}$ & $\begin{array}{l}\text { tv-novela } \\
\text { cómico }\end{array}$ & $\begin{array}{l}\text { cómico } \\
\text { variedad }\end{array}$ \\
\hline
\end{tabular}

* Por estratos sociales

Fuentes:

BLANCO SÁNCHEZ, Jorge. (1996). Oferta de programas nacionales y extranjeros en medios televisivos y análisis de su exposición y consumo por alumnos de secundaria en la ciudad de Irapuato. Tesis de Maestria. Instituto Tecnológico y de Estudios Superiores de Monterrey, Monterrey, Nuevo León.

DE LA GaRZA YAÑEZ, Yamille. (1996). Patrón de exposición y preferencias programáticas televisivas de los jóvenes de preparatoria de Monterrey y su área conurbada. Tesis de Maestría. Instituto Tecnológico y de Estudios Superiores de Monterrey, Monterrey, Nuevo León.

Diaz VIELBA, Ma. del Rocío. (1995) Oferta de mensajes televisivos extranjeros en Monterrey, N.L. y las preferencias programáticas de los jóvenes de secundaria. Tesis de Maestría. Instituto Tecnológico y de Estudios Superiores de Monterrey, Monterrey, Nuevo León.

Figueroa DAZA, Jaime. (1996). Oferta y consumo de programas televisivos extranjeros. Un análisis en los alumnos de secundaria de la Ciudad de México. Tesis de Maestría. Instituto Tecnológico y de Estudios Superiores de Monterrey, Monterrey, Nuevo León.

LOZANo, José Carlos. (1994). "Recepción y uso de medios de comunicación en los jóvenes fronterizos". en José Carlos Lozano (ed.). Anuario de la Investigación de la comunicación CONEICC I. México: CONEICC.

MÁRQUez De LA GARZA, Myrna (1996). El papel de las mediaciones en niños de primero de primaria: Un estudio de recepción. Tesis de Maestría. Instituto Tecnológico y de Estudios Superiores de Monterrey, Montertey, Nuevo León.

Olvera EsCAmilla, Humberto. (1995). Análisis de la relación entre la oferta de programación nacional en medios televisivos y su recepción por alumnos de secundaria de la ciudad de Zacatecas. Tesis de Maestría. Instituto Tecnológico y de Estudios Superiores de Monterrey, Monterrey, Nuevo León. 


\section{¿Cómo se exponen los televidentes?}

A continuación se presentan las investigaciones mexicanas sobre recepción televisiva que se realizaron con técnicas. En ellas se analiza la apropiación y las mediaciones intervinientes en el proceso de recepción.

En la revisión de la literatura se encontró que los estudios que se enfocan a conocer el uso y apropiación de los mensajes televisivos están basados en los argumentos de la recepción activa y las mediaciones que influyen en la producción del sentido.

Para un mejor entendimiento de lo que se expondrá se clasificaron los trabajos en función de los agentes mediadores en que se enfocan los estudios.

En su estudio acerca de la recepción de las telenovelas (Colima, Ciudad de México, Guadalajara, León, Puebla y Veracruz ), González(1993) y su equipo realizaron también un análisis cualitativo por medio de un "Protocolo de observación" que requería la relación de manera cotidiana y en vivo de los investigadores con varias familias (de las cuales se habian obtenido anteriormente información mediante el cuestionario). El esfuerzo anterior tenía como fin " [...] obtener descripciones densas de algunas relaciones entre vida diaria, televisión y telenovelas en el contexto de diversas familias mexicanas" (González, 1993: 324-325). En forma global González concluye que la telenovela como producto cultural muy consumido (corroborado con el estudio cuantitativo) de uno de los difusores (TV) del grupo simbólico masmediático es "leída" desde el grupo primario familiar, que como "unidad doméstica" precondiciona dicha "lectura" discursiva del texto a partir de sus características propias de estrato, cultural, contexto y dinámicas que ejerce dentro de la sociedad.

A partir de lo anterior se puede concluir que si bien la familia con sus cosmovisiones precondicionan la recepción que sus integrantes hacen de la televisión, ésta será una recepción matizada por la cultura a la que la familia pertenece. Lo cual da la posibilidad de resemantizar los mensajes. Esta resemantización provocada por la mediación familiar podría -en el mejor de los casos-crear una adecuación y adaptación de los mensajes transnacionales a las distintas identidades culturales de las audiencias.

Por su parte, Cornejo (1994) presenta una alternativa metodológica para investigar los procesos de recepción televisiva en los niños, basada en el psicodrama técnica que " [...] permite reconstruir y recrear desde la acción la recepción televisiva de los niños, considerando las vivencias socio-afectivas ocurridas en la cultura de los televidentes infantiles que los hacen interactuar de cierta manera con la familia, los maestros, los amigos" (Cornejo,1994: 90). Para mostrar el procedimiento de esta técnica, la autora 
reseña un trabajo psicodramático que realizó con alumnos de sexto de primaria de una escuela de la Ciudad de México.

La dramatización presentada nos permite percibir de una manera bastante clara el momento en que Alin ve TV. Gracias a esta puesta en escena podemos explorar el mundo familiar en el que nuestra protagonista se desarrolla (Cornejo,1994: 102).

\section{Estudios de mediaciones y apropiación}

A continuación se presentan las investigaciones que parten de la combinación de mediaciones familiares y escolares como comunidades de interpretación de los niños. Autores como Cornejo et al (1995), Márquez (1996) y Orozco (1993) han estudiado los procesos de apropiación de los mensajes televisivos de los niños de primaria desde el ámbito escolar.

\section{Recepción televisiva infantil y sus mediaciones}

"Detectar la importancia de la TV en la cotidianeidad de distintas audiencias infantiles y el papel mediador de padres y maestros en su proceso de recepción televisiva" (1993: 263) fue el objetivo de un estudio realizado por Orozco el cual se llevó a cabo a través de 174 entrevistas a profundidad realizadas a niños de sexto grado de primaria que asistían a siete diferentes escuelas de la Ciudad de México.

De entre los resultados tenemos que en el estrato socioeconómico bajo "Las mediaciones que influyeron en las distintas interpretaciones fueron el lugar de ubicación de la escuela y las expectativas de movilidad social de sus padres, combinadas con las expectativas educativas de las madres" (Orozco, 1993: 290-291). En el estrato medio se encontró que " [...] estos niños son objeto de mediaciones contradictorias, tanto en el seno familiar como entre la familia y la escuela." (Orozco, 1993: 291). En los niños de estrato alto que asistían a escuela con propuesta pedagógica liberal la interpretación de los mensajes se llevó a cabo al margen de la comunidad de apropiación (grupo de personas con las que usualmente se ve la TV), generando la interpretación a partir de la propuesta televisiva; mientras que aquellos que asistían a escuela con métodos tradicionales, la familia -en tanto comunidad de referencia y apropiación-fue la que predominó. 
Mediante observación participante y entrevistas en profundidad a niños de primer grado de primaria en la ciudad de Monterrey, Márquez (1996), por su parte, se planteó conocer las mediaciones en el proceso de recepción de los escolares pertenecientes a diferentes clases sociales (alta y baja). La autora encontró que los niños de clase alta mencionaron solamente personajes de televisión extranjeros y los de clase baja mencionaron tanto extranjeros como nacionales. Algunos maestros -los de colegios privadosse apoyan en la televisión para hacer su explicaciones, mientras otros -los de escuelas públicas-ignoran los comentarios que los niños hacen acerca de la TV. Los niños de la clase baja tienen dentro de su comunidad de apropiación a los padres -quienes en la mayoría de los casos eligen qué ver en la TV, mientras la comunidad de apropiación de los niños de clase alta está conformada por los hermanos, esto es, son los niños de este estrato quienes mayormente eligen a lo que se exponen.

\section{La escuela como agente mediador}

Por medio del estudio de la propuesta educativa institucional en lo referente al uso de la televisión y demás medios informáticos y audiovisuales, Cornejo et al (1995) dan cuenta, desde el ámbito escolar, de las relaciones que se establecen de manera rutinaria en los niños (de 11 a 13 años de edad) de una escuela de Polanco en la Ciudad de México. Los autores encontraron que desde el proyecto pedagógico se desplaza hacia el ámbito familiar la relación niño-televisión. Los autores concluyen explicando:

[...] la relación de los escolares con la televisión, va más allá de la normatividad que los adultos establecen con respecto a su uso pedagógico tanto en la práctica educativa cotidiana, como en el proyecto institucional. Esto se revela a través de las negociaciones y disputas entre los valores adultos -realismo, responsabilidad-y los valores púberes -imaginación, creatividad y diversión- que se confrontan con emotividad día a día dentro del aula (Cornejo et al, 1995: 238).

La escuela, en tanto institución social (Aunque los maestros de manera individual, desde la escuela, influyen en las apropiaciones de los mensajes televisivos), según lo encontrado en los estudios anteriores, no se revela como gran influencia mediadora en la forma en que los niños realizan la recepción, no forma parte del currículo la comprensión de los medios como grupo simbólico, ni como apoyo estructural en las técnicas de los 
docentes. De esta manera, como marco de referencia de los niños, que interviene en la generación de su identidad cultural, no rechaza ni apoya la posible influencia de los mensajes extranjeros sobre ellos.

\section{La familia como agente mediador}

A partir de aqui se presentan las investigaciones en las que los autores se concentraron en dilucidar las mediaciones familiares dentro del proceso de recepción televisiva infantil. Estas mediaciones pueden ser, según Orozco (citado en Cornejo, 1992:43): la presencia familiar, el tipo de comunicación familiar, el patrón de disciplina, el estatus que la TV detenta y la percepción familiar de su rol mediador. Todos estos factores llegan a condicionar la apropiación que de los mensajes hacen los niños.

"¿Cómo los niños 'miran' la televisión, luego que su 'modo de ver' pueda ser modificado y tamizado y además mediado por la familia?", responder a esta pregunta fue el objetivo del estudio de Inés Cornejo (1992b: 40) en el que por medio del psicodrama explora la forma en que los niños de sexto grado de una escuela en la Ciudad de México son mediados por la institución familiar. La autora obtuvo los siguientes hallazgos:

Las escenas presentadas [dramatizaciones protagonizadas por los escolares] nos revelan que en el procedimiento de recepción de los televidentes infantiles, entran en juego una serie de factores (el tipo de comunicación familiar, el método disciplinario, la orientación de la familia, el estatus de la televisión en el hogar) que conforman la estrategia familiar -consciente o inconsciente-para mediar la recepción televisiva de los niños. [...] La mayoría de las escenas nos muestran que la televisión es utilizada por los padres como medida de control -cuando los niños tiene que cumplir requerimientos previos para poder verla-, y como medida disciplinaria -cuando los padres utilizan la televisión como premio o castigo. Se percibió que, la mayoría de los hogares presentan, en su cotidianeidad, una combinación de ambas (Cornejo, 1992: 60).

Renero (1992b), por medio de entrevistas focalizadas realizadas a ocho parejas (padres de familia) de la Ciudad de México, se planteó como preguntas: ¿Para qué sirve la TV -a través de los géneros-a las familias mexicanas? y ¿ De qué manera el uso cotidiano de 
estos géneros refuerza la caracterización en el ámbito familiar de identidades sociales entre generaciones y sexos? la autora presenta los siguientes resultados:

[...] en las representaciones de los géneros televisivos por parte de los padres de familia -que también son proyectados a sus hijos e hijas-, trasluce un activo aprendizaje de los 'modos adecuados de ser' en relación a su medio socio-cultural. [...] la situación recurrente de que ambos padres de familia descalifican al género tildándolo de 'irreal' o de 'mal ejemplo', cuando sienten que su capacidad para guiar a sus hijos ( a través de adecuadas re-interpretaciones y apropiaciones de lo televisivo), se ve desprestigiada por la mayor verosimilitud y actualidad de las significaciones televisivas, percibidas por los padres como 'favoritas' de sus hijos (Renero, 1992b:36).

Por su parte, Orozco (1992) busca la influencia de la mediación familiar por medio de la madre y sus respectivas "teorías educativas" , que, como las define el autor, son una combinación de filosofía pedagógica, aspiraciones sociales y percepción de la televisión en el desarrollo educativo de los niños. Por medio de entrevistas en profundidad realizadas a 28 madres de la Ciudad de México (se eligieron a las señoras a partir de las siete escuelas de las que ya se presentaron resultados [Orozco, 1993] en este mismo trabajo). En términos generales el autor plantea:

El común denominador de las 7 audiencias abordadas fue el hecho de que las madres perciben la televisión como algo que no es neutral para la educación de los niños y como una fuente de influencia en su desarrollo. Las variaciones entre las audiencias estuvieron relacionadas con el peso específico que las madres, en cada una de ellas, asignaron a dicha influencia. (Orozco, 1992: 13-14).

Lo anterior deja traslucir que dependiendo de la "teoria educativa" que la madre tiene será el tipo de mediaciones que ejerza sobre el niño.

En un estudio sobre la misma línea, Renero (1992a) explora las mediaciones que ejerce la madre en función del estrato sociocultural al que pertenece. Para lograr su objetivo se realizó un análisis a partir del discurso de 25 entrevistas realizadas a madres de Tijuana, las cuales fueron elegidas según su estrato. A las madres de estrato sociocultural bajo la autora las denomina 'audiencia mixteca' (ya que emigraron de Oaxaca a Tijuana), sus hijos asisten a escuelas públicas, y denomina a las madres de estrato alto 'audiencia privada', sus hijos asisten a escuela privada. La autora concluye: 
Podemos decir que el carácter tradicional de la audiencia mixteca se refiere al Énfasis en el ordenamiento del tiempo. En este modo de 'socialidad' resulta imprescindible la intervención directa de la madre, con su estilo comunicativo autoritario a base de órdenes y concesión o negación de permisos, pero en cuyo eje central de significación se encuentra la re-valorización del consejo materno como modo de orientar a los hijos pequeños sobre la dimensión moral de la vida. [...] Por otro lado, el carácter moderno de la audiencia privada se refiere al Énfasis en la dimensión de la 'tecnicidad', es decir, en la preocupación materna por aumentar al caudal de recursos culturales para que sus hijos aprendan a codificar nuevas informaciones y elaboraciones videotecnológicas. En este sentido más que enfatizar su capacidad de mando, la madre manifiesta un estilo de comunicación participativo abierto a diferentes puntos de vista, incluso hasta contrarios a sus propias convicciones (Renero, 1992a: 52).

Así mismo, Renero (1995) realizó otro estudio con la misma metodología que el anterior, pero esta vez incluyó la Ciudad de México (40 madres de familia en total), teniendo como objetivo delinear distintos usos sociales de la televisión y otros medios a partir del discurso generado por las madres. En lo que respecta a los hallazgos referentes al medio televisivo la autora nos dice:

[...] entre las madres de la audiencia de escuelas privadas de ambas ciudades, se observa una practica de recepción más motivada por expectativas de ascenso social, acompañada de una deliberada actividad selectiva. [...] sólo entre los padres de familia de las escuelas privadas (aunque especialmente de la capital), se advierte una postura ciudadana de exigencia para que la institución televisiva ofrezca una programación más variada y de mayor calidad que cubra las necesidades informativas, de entretenimiento, educación y cultura de públicos cada vez más diferenciados y exigentes (Renero, 1995:152).

La percepción de los padres acerca de la televisión, sus mensajes, sus propuestas, y el uso que de Ésta hacen, es de alguna manera "heredado" a los hijos. Esta.mediación -la familiar- es una de las más fuertes que encontramos en las instituciones sociales. Independientemente del tipo de mediación (de las propuestas por Orozco) que en la familia sucedan, siempre irán impregnadas de la ideología familiar. Esta situación puede permitir el rechazo a mensajes que no comulguen con su ideología, como pueden ser los mensajes extranjeros, que en la mayoría de los casos se encuentran fuera del contexto cultural del país receptor. 
Con lo analizado en lo referente a las investigaciones cualitativas podemos damos cuenta que los estudios que se acercan más al receptor, esto es, estudiando su formas de apropiación, usos y asimilación de los mensajes. Sin embargo, la mayoría de los estudios no se han concentrado en estudiar la recepción de mensajes transnacionales, por lo que no se pueden hacer afirmaciones alrededor de la pérdida de identidad cultural o alguna otra clase de influencia sobre Ésta.

\section{Conclusiones}

En lo que respecta a la preocupación de las posibles influencias de los mensajes transnacionales, se concluye a través de la revisión de 19 estudios mexicanos sobre recepción televisiva que aunque la oferta de programación extranjera en la mayoría de las ciudades estudiadas sea mayor que la de producción nacional, la población analizada prefiere en su mayoría lo nacional.

La segunda sección de este estudio parece refutar las afirmaciones de los imperialistas culturales, por lo menos en lo referente al receptor. Aunque no se han hecho estudios particulares del consumo de mensajes extranjeros en México, al menos los resultados de estos académicos sugieren que el receptor es activo y que esté sujeto a una serie de mediaciones que en el mejor de los casos lo pueden proteger de los mensajes hegemónicos. Ahora bien, el hecho de que "El canal de las estrellas" sea el favorito de muchos mexicanos, no significa que los receptores reciban solamente valores y visiones del mundo netamente nacionales, ya que sería interesante analizar los contenidos de ese canal y evaluar si no estamos siendo víctimas de un imperialismo cultural representado por el modelaje, la imitación de géneros, formulas y estructuras norteamericanas.

Lo establecido por los culturalistas se puede constatar -especialmente lo referente a las mediaciones-en los resultados arrojados por los estudios cuantitativos, ya que como podemos ver en el Cuadro 1, los hombres prefieren las producciones extranjeras, mientras las mujeres prefieren las producidas a nivel nacional. Este es un claro ejemplo de cómo el género del individuo media sus procesos de recepción. $O$ el caso de que en la mayoría de la ciudades el estrato que prefiere la programación extranjera es el alto, lo que ilustra cómo el nivel socioeconómico también representa una fuente de mediación.

Además, lo anterior sirve para apoyar el hecho de que los simpatizantes de las corrientes críticas pueden utilizar técnicas cuantitativas y obtener hallazgos que soporten sus estudios. 
El estado de los estudios de recepción televisiva en México se presenta de la siguiente forma (la propuesta estriba en mejorar la situación descrita a continuación):

En cuanto a su espacialidad, se concentran en pocas ciudades y se encuentran dispersos. Su carácter transversal no permite comparar el comportamiento de las audiencias a través del tiempo. Las unidades de análisis en su mayoría son niños y adolescentes. A excepción del estudio realizado por González sobre la recepción de telenovelas (1993), los académicos se centran en las audiencias jóvenes. Los del enfoque culturalista son los más preocupados por este fenómeno. Mayores aportaciones a la investigación de la comunicación podrian hacerse si académicos con otra formación, desde su perspectiva y visión, analizaran los procesos de recepción y consumo de televisión.

Pero lo anterior puede tener su origen y explicación en la tres veces marginal condición de la investigación mexicana en comunicación. (Fuentes y Sánchez Ruiz, 1992: 23):

[...] (dentro de las ciencias sociales, a su vez marginales dentro de la actividad científica general y Ésta en relación con las prioridades del desarrollo nacional); por lo tanto pobre (en términos de los recursos asignados a ella), además extremadamente centralizada y 'generalista', dispersa (en términos temáticos y teórico-metodológicos), instrumentalizada, pretenciosa y autoritaria, hipercrítica, en ocasiones ideológicamente dependiente, antiempirista, dada a las modas, sesgada al estudio de los medios.

Por lo pronto, sabemos a través de este condensador estudio que los tres veces temibles y temidos mensajes extranjeros tiene dos guardabarreras: La recepción activa con sus mediaciones y la preferencia de los mexicanos (de las muestras analizadas) por la programación nacional.

\section{Bibliografia y referencia biblográficas}

AcEves GonZÁlez, Francisco. (1991). " La televisión y los tapatíos. Un atisbo al entreveramiento horario de transmisión, menú programático y patrones de exposición". Comunicación y sociedad. Núm. 13 (septiembre - diciembre).

BILTEREYST, Daniel. (1995). "Qualitative audience research and transnational media effetcs. A new paradigm". European journal of communication., Vol 10. Londres: SAGE. 
BLANCO SÁNCHEZ, Jorge. (1996). Oferta de programas nacionales y extranjeros en medios televisivos y análisis de su exposición y consumo por alumnos de secundaria en la ciudad de Irapuato.Tesis de Maestría. Instituto Tecnológico y de Estudios Superiores de Monterrey, Monterrey, Nuevo León.

CORNEJo PORTugal, Inés. (1992). "El psicodrama aplicado al estudio de la recepción familiar televisiva". Comunicación y sociedad. Núm 14 -15 (enero - agosto).

- (1994). "¿Cómo la ves?. El psicodrama aplicado para el estudio de la recepción televisiva de los niños". en Guillermo Orozco (coord). Televidencia. Perspectivas para el análisis de los procesos de recepción televisiva. México: Universidad Latinoamericana.

----(1995). "Televisión sí, pero con orden". en José Carlos Lozano (ed.). Anuario de la Investigación de la Comunicación CONEICC II. México: CONEICC.

DE La GarZa YañeZ, Yamille. (1996)." Patrón de exposición y preferencias programáticas televisivas de los jóvenes de preparatoria de Monterrey y su área conurbada".Tesis de Maestría. Instituto Tecnológico y de Estudios Superiores de Monterrey, Monterrey, Nuevo León.

DíAZ VIELBA, Ma. del Rocío. (1995)"Oferta de mensajes televisivos extranjeros en Monterrey, N.L. y las preferencias programáticas de los jóvenes de secundaria". Tesis de Maestría. Instituto Tecnológico y de Estudios Superiores de Monterrey, Monterrey, Nuevo León.

Figueroa DAZA, Jaime. (1996)." Oferta y consumo de programas televisivos extranjeros. Un análisis en los alumnos de secundaria de la Ciudad de México". Tesis de Maestría. Instituto Tecnológico y de Estudios Superiores de Monterrey, Monterrey, Nuevo León.

FuENTES NAVARRo, Raúl y Enrique Sánchez Ruiz. (1992). "Investigación sobre comunicación en México: los retos de la institucionalización". en Guillermo Orozco (coord). Cuadernos de comunicación y practicas sociales. Universidad Iberoamericana . Núm. 3, México

GonZÁlEZ, Jorge. (1993). "La cofradia de las emociones in/terminables. Telenovela, memoria, familia". En Nestor García Canclini (coord). El consumo cultural en México. México: Conaculta.

(1994). "La cofradía de las emociones (in)terminables. Construir las telenovelas mexicanas". Más (+) Cultura (s). Ensayos sobre realidades plurales. México: Conaculta. 
LozANo, José Carlos. (1994). "Recepción y uso de medios de comunicación en los jóvenes fronterizos". en José Carlos Lozano (ed.) Anuario de la Ivestigación de la Comunicación CONEICC I. México: CONEICC.

(1996). Teoría e Investigación de la Comunicación de Masas. México: Alhambra Universidad.

Márquez De la Garza, Myrna (1996). "El papel de las mediaciones en niños de primero de primaria: Un estudio de recepción". Tesis de Maestria. Instituto Tecnológico y de Estudios Superiores de Monterrey, Monterrey, Nuevo León.

Olvera Escamilla, Humberto. (1995). "Análisis de la relación entre la oferta de programación nacional en medios televisivos y su recepción por alumnos de secundaria de la ciudad de Zacatecas".Tesis de Maestría. Instituto Tecnológico y de Estudios Superiores de Monterrey, Monterrey, Nuevo León.

Orozco GómEz, Guillermo. (1992). "Familia, televisión y educación en México". en Guillermo Orozco (comp)., Hablan los televidentes. estudios de recepción en varios paises. Universidad Iberoamericana, Cuadernos de Comunicación y practicas sociales. Núm 4, . México

------ (1993). "Cultura y televisión de las comunidades de referencia a la producción de sentido en el proceso de recepción". en Nestor García Canclini (coord). El Consumo Cultural en México. México: Conaculta.

----o (1994). "Recepción televisiva y mediaciones. La construcción de estrategias por la audiencia". en Guillermo Orozco (coord). Televidencia. Perspectivas para el análisis de los procesos de recepción televisiva. Universidad Iberoamericana, México.

RENERo QuinTANAR, Martha. (1992a). "La mediación familiar en la construcción de la audiencia". en Guillermo Orozco (coomp). Hablan los televidentes. Estudios de recepción en varios países., Universidad Iberoamericana. Cuadernos de Comunicación y practicas sociales. Núm 2. México

(1992b). "De géneros televisivos y usos familiares". Comunicación y sociedad. Núm 14 -15 (enero - agosto).

- (1995). "Audiencias selectivas en el entorno de la oferta multiplicada; el discuros materno acerca de los usos de la televisión y otros medios". Comunicación y sociedad. Núm 24 (mayo- agosto).

RotA, Josep y Clemencia Rodriguez. (1995). " Propuesta para una nueva agenda de investigación sobre comunicación internacional". Comunicación y sociedad. Núm.24 (mayo - agosto). 